\title{
DETERMINAN KINERJA KARYAWAN: STUDI PADA SEKTOR PARIWISATA DI KABUPATEN BULELENG
}

\author{
I Gusti Ayu Purnamawati \\ Gede Adi Yuniarta \\ Fakultas Ekonomi, Universitas Pendidikan Ganesha \\ Email: ayupurnama07@yahoo.com
}

\begin{abstract}
Abstrak
Penelitian ini bertujuan untuk mengetahui determinan kinerja karyawan di sektor pariwisata. Penelitian ini dilakukan pada hotel-hotel berbintang yang ada di Kawasan Lovina Kabupaten Buleleng Bali. Penelitian ini menggunakan pendekatan kuantitatif. Data yang digunakan dalam penelitian ini adalah data primer yaitu diperoleh dengan menggunakan kuesioner atau daftar pertanyaan yang telah terstruktur dengan tujuan untuk mengumpulkan informasi dari karyawan dengan menggunakan skala likert 1-5. Populasi dalam penelitian ini adalah karyawan bagian akuntansi pada hotel-hotel berbintang di Kawasan Lovina. Teknik pengambilan sampel yang digunakan menggunakan metode purposive sampling. Sampel pada penelitian ini berjumlah 13 Hotel Berbintang yang ada di Kawasan Lovina dengan jumlah responden sebanyak 47 orang karyawan. Pengujian hipotesis menggunakan model logistic regression binary dengan tingkat signifikan (a) 5\%. Hasil penelitian menunjukkan bahwa variabel Gaya Kepemimpinan, Sistem Pengendalian Internal, Partisipasi Penyusunan Anggaran, Job Relevant Information, Motivasi, Budaya Organisasi, Gender dan Grade Jabatan berpengaruh positif dan signifikan terhadap Kinerja Karyawan.
\end{abstract}

Kata kunci: Kinerja, Karyawan, Kepemimpinan, Motivasi, Jabatan.

\begin{abstract}
This study aims to determine the determinants of employees performance in the hospitality sector. This study was conducted at five-star hotels in Lovina area (Buleleng Regency, Bali). This study uses a quantitative approach. The data used in this research is the primary data which obtained by using a questionnaire or a list of questions that have been structured with the aim of gathering information from employees using Likert scale 1-5. The population in this study are employees of the accounting department at the luxury hotels in Lovina area. The sampling technique used purposive sampling method. Samples in this study amounted to 13 Starred Hotels in Lovina area with a number of respondents as many as 47 employees. Hypothesis testing using binary logistic regression models with a significant level $(\alpha)$ of $5 \%$. The results showed that the variables of Leadership Style, Internal Control Systems, Budgeting Participation, Job Relevant Information, Motivation, Organizational Culture, Gender and Position Grade has positive and significant impact on employee performance.
\end{abstract}

Keywords: Performance, Employees, Leadership, Motivation, Occupation. 


\section{PENDAHULUAN}

Sektor pariwisata telah banyak dikembangkan oleh negara-negara di dunia sebagai penghasil devisa. Pariwisata diidentikkan dengan industri ramah lingkungan karena tik menimbulkan dampak negatif terhadap lingkungan jika dibandingkan dengan industri berat lainnya. Maraknya Industri pariwisata saat ini dengan segala jenis fasilitas dan kenyamanan yang ditawarkan masih menjadi daya tarik yang dominan di Provinsi Bali. Sebagai daerah tujuan wisata maka pulau Bali konsisten untuk menempatkan sektor pariwisata sebagai sektor andalan (Antari, 2013). Industri pariwisata merupakan suatu rangkaian dari unit-unit usaha yang menghasilkan barang dan jasa yang dibutuhkan oleh wisatawan baik secara langsung maupun tidak langsung. Seiring dengan meningkatnya peran sektor pariwisata di Provinsi Bali maka diharapkan dapat ikut memberikan kontribusi terhadap peningkatan Pendapatan Asli Daerah. Provinsi Bali memiliki obyek wisata yang beragam baik itu wisata alam, sejarah maupun budaya. Sektor pariwisata memiliki peran dan fungsi yang strategis dalam pembangunan, selain sebagai penghasil devisa bagi negara dan pendapatan bagi daerah, jika dilihat dari aspek ekonomi maka sektor ini juga dapat meningkatkan kesejahteraan masyrakat dengan memberikan sumbangan positif di sektor perekonomian lainnya transportasi, komunikasi, pertanian, perdagangan, dan lainnya.

Melalui revisi Rencana Tata Ruang Kawasan Provinsi bali dimana ditetapkan 15 kawasan wisata dan 6 kawasan sebagai ODTW khusus yang telah ditetapkan tersebut, 14 kawasan dan 3 ODTW khusus merupakan kawasan pantai. Wilayah Bali Utara yaitu Kabupaten Buleleng memiliki banyak daya tarik objek wisata yang memberikan kontribusi dalam peningkatan Pendapatan Asli Daerah yaitu sebesar 3.187.926.327,18 atau $119,44 \%$ pada tahun 2014 (Dinas Pendapatan Pemkab Buleleng, 2014). Menurut Disbudpar Kabupaten Buleleng kawasan Lovina sementara menjadi pusat fasilitas kepariwisataan di kabupaten Tingkat II Buleleng. Namun perkembangan pariwisata di kawasan Lovina cenderung mengalami penurunan. Pengelolaan pariwisata Lovina belum dapat mengikuti tren perkembangan pariwisata ditengah kompetisi destinasi wisata yang semakin ketat saat ini. Dimana kurangnya kenyamanan wisatawan dan fasilitas yang minim menjadi salah satu kendala utama.

Sumber daya manusia yang kurang pengalaman dan profesional menurunkan persepsi wisatawan mengenai pelayanan dan kenyamanan (Pertiwi, 2012). Untuk meningkatkan kualitas sumber daya manusia itu sendiri, maka perubahan harus dimulai dari tingkat yang paling atas yaitu pimpinan yang memberi panutan terhadap bawahannya. Setiap pemimpin pada dasarnya memiliki perilaku yang berbeda dalam memimpin atau sering disebut dengan gaya kepemimpinan. Kepemimpinan meliputi proses mempengaruhi dalam menentukan tujuan organisasi, memotivasi perilaku pegawai untuk mencapai tujuan, mempengaruhi untuk memperbaiki kelompok dan budayanya (Hersay \& Blanchard, 2001). Gaya kepemimpinan merupakan proses interaksi antara seseorang (pemimpin) dengan sekelompok orang yang menyebabkan seseorang atau kelompok berbuat yang sesuai dengan kehendak pemimpin (Nawawi, 2003). Penelitian Yunista (2013), hasil penelitian menunjukkan bahwa kepemimpinan dan lingkungan kerja berpengaruh positif dan signifikan terhadap kinerja karyawan. Penelitian Sari (2013) mengenai pengaruh kepemimpinan dan motivasi kerja terhadap kinerja karyawan galeri Ciumbuleuit hotel dan apartemen Bandung menyatakan bahwa secara parsial kepemimpinan dan motivasi kerja karyawan memiliki pengaruh yang signifikan terhadap kinerja karyawan. Penelitian Mulyanto (2011) dimana kepemimpinan berpengaruh positif dan signifikan terhadap kinerja pegawai dengan kepuasan kerja sebagai variabel moderating.

Dalam kaitannya dengan kinerja karyawan, maka sistem pengendalian internal memiliki peran penting. Sistem Pengendalian Internal (SPI) berfungsi sebagai pengatur sumberdaya yang telah 
ada untuk dapat difungsikan secara maksimal guna memperoleh pengembalian (gains) yang maksimal pula dengan pendekatan perancangan yang menggunakan asas Cost-Benefit (Indah, 2012). Bastian (2009) mengungkapkan bahwa tujuan SPI adalah untuk meningkatkan kinerja organisasi, melindungi harta/aktiva organisasi dan pencatatan pembukuannya, mengecek kecermatan dan keterandalan data akuntansi, meningkatkan efisiensi usaha dan mendorong ditaatinya kebijakan manajemen yang telah ditetapkan. Usman (2013), hasil penelitian menunjukkan bahwa Sistem Pengendalian Intern berpengaruh positif terhadap Kinerja Perusahaan.

Job Relevant Information (JRI) merupakan informasi internal organisasi yang berkaitan dengan tugas yang dihasilkan oleh karyawan. Informasiinformasi tersebut dapat memberikan prediksi lingkungan dengan lebih tepat serta memungkinkan pilihan suatu kebijakan yang lebih baik untuk selanjutnya dapat memperbaiki kinerja. Early (1987) menguji pengaruh tujuan yang ditetapkan dengan informasi yang relevan dengan tugas (job relevant) terhadap kinerja, dan energy yang dikeluarkan dan perencanaan tugas. Hasil penelitiannya menyimpulkan bahwa informasi yang relevan dengan tugas akan mendorong aktivitas perencanaan dan cara pendekatan yang digunakan terhadap tugas, serta membuat individu akan lebih keras berusaha dan lebih bersemangat dalam mengerjakan tugas dibandingkan individu yang tidak memiliki informasi job relevant (Pratiwi, 2005). Yusfaningrum \& Ghozali (2005) memahami informasi berhubungan dengan tugas (Job Relevant Information) sebagai informasi yang memfasilitasi pembuatan keputusan manajerial. Penelitian Putra (2014) mengenai pengaruh partisipasi dalam penyusunan anggaran terhadap kinerja manajerial pada SKPD Kabupaten Buleleng melalui komitmen organisasi, kecukupan anggaran, komitmen tujuan anggaran dan job relevant information sebagai variabel moderating, hasilnya menyatakan bahwa terdapat pengaruh yang signifikan dan positif antara partisipasi penyusunan anggaran terhadap kinerja manajerial dengan Job relevant information (JRI) sebagai variabel moderasi pada SKPD Kabupaten Buleleng. Penelitian Nengsy, dkk (2013) mengenai pengaruh partisipasi penyusunan anggaran terhadap kinerja manajerial dengan job relevant information, kepuasaan kerja dan motivasi sebagai variabel intervening, hasilnya menyatakan bahwa pada SKPD di Kabupaten Indragiri Hilir Job relevant information tidak dapat memediasi hubungan antara partisipasi penyusunan anggaran dengan kinerja manajerial. Ini artinya informasi yang berhubungan dengan tugas yang dimiliki oleh Pejabat Struktural SKPD kabupaten Indragiri Hilir tidak menjadi patokan dalam meningkatkan kinerja manajerial.

Ketika seorang karyawan terlibat dalam pengambilan keputusan penganggaran, maka ia akan termotivasi dalam situasi kelompok karena diberi kesempatan untuk mewujudkan inisiatif dan daya kreatifitas. Tujuan bersama akan lebih mudah tercapai sehingga ada keterlibatan secara pribadi dan kesediaan untuk menerima tanggungjawab masingmasing. Rasa tanggungjawab ini pada akhirnya akan memperkuat kreativitas manajer yang bersangkutan. Widanarta (2003) menyebutkan bahwa partisipasi anggaran dapat memengaruhi sikap/usaha pencapaian sasaran dari kinerja manajer. Mattola (2011), hasil penelitian menunjukkan bahwa partisipasi anggaran berpengaruh positif terhadap kinerja.

Untuk mencapai tujuan organisasi, pemimpin harus dapat menciptakan kondisi yang dapat mendorong karyawan untuk mengembangkan diri, meningkatkan kemampuan serta karyawan dapat termotivasi untuk menyelesikan tugastugasnya dengan baik dan cepat. Menurut Hasibuan (2007) mengatakan bahwa motivasi adalah pemberian daya penggerak yang menciptakan kegairahan kerja seseorang, agar mereka mau bekerjasama, bekerja efektif dan terintekrasi dengan segala daya upayanya untuk mencapai kepuasan. Motivasi yang dimiliki oleh pegawai untuk bekerja adalah kunci kesuksesan dalam organisasi. Menurut Hafizurrahcman (2007), karakteristik pekerja yang mempunyai motivasi berprestasi tinggi, antara lain: 1) 
Memiliki tanggung jawab pribadi yang tinggi, 2) Memiliki Program kerja berdasarkan rencana dan tujuan nyata serta berjuang untuk merealisasikannya, 3) Memiliki kemampuan untuk mengambil keputusan dan berani mengambil risiko yang dihadapinya, 4) Melakukan pekerjaan yang berarti dan menyelesaikan dengan hasil yang memuaskan, dan 5) Mempunyai keinginan menjadi orang terkemuka yang menguasai bidang tertentu. Penelitian Windayani (2013) mengenai pengaruh komunikasi dan motivasi terhadap kinerja pegawai pada Dinas Perhubungan Kabupaten Buleleng, hasilnya yaitu komunikasi dan motivasi berpengaruh positif dan signifikan terhadap kinerja pegawai pada Dinas Perhubungan Kabupaten Buleleng. Ismuhadjar (2006), dimana motivasi berpengaruh positif dan signifikan terhadap kinerja pejabat struktural dan dosen tetap dibeberapa perguruan tinggi swasta di Jakarta.

Budaya organisasi atau budaya kerja merupakan sistem nilai-nilai yang diyakini semua anggota organisasi dan yang dipelajari, diterapkan, serta dikembangkan secara berkesinambungan, berfungsi sebagai sistem perekat, dan dapat dijadikan sebagai acuan berperilaku dalam organisasi untuk mencapai tujuan organisasi yang telah ditetapkan. Hofstede (1990) membagi budaya organisasional ke dalam enam dimensi: 1) Inovasi dan pengambilan resiko. Sejauh mana anggota organisasi didorong untuk inovatif dan mengambil resiko; 2) Perhatian ke hal yang rinci. Sejauh mana anggota organisasi diharapkan mampu menunjukkan ketepatan, analisis dan perhatian pada hal yang rinci; 3) Orientasi hasil. Sejauh mana para pimpinan berfokus pada hasil dan bagaimana orientasi para pimpinan pada proses/teknik yang dilakukan untuk mencapai hasil; 4) Orientasi orang, Sejauh mana keputusan-keputusan pimpinan mempertimbangkan efek hasil pada anggota organisasi; 5) Orientasi kelompok. Sejauh mana aktifitas kerja diorganisasikan dalam kelompokkelompok kerja dibandingkan pada kerja individual; 6) Keagresifan. Kondisi agresifitas dan kompetisi anggota organisasi. Penelitian Koesmono (2005) menyatakan bahwa budaya organisasi berpengaruh positif terhadap kinerja pegawai. Budaya organisasi juga berpengaruh positif terhadap motivasi dan kepuasan kerja pegawai. Daryatmi (2005) menyatakan bahwa budaya organisasi mempunyai pengaruh positif dan signifikan terhadap produktifitas kerja karyawan.

Dalam sebuah instansi, suatu perbedaan peran antara laki-laki dan perempuan yang sering disebut dengan isitilah "gender" juga sering muncul. Menurut Mulia (2004) gender adalah suatu konsep kultural yang dipakai untuk membedakan peran, perilaku, mentalitas dan karakteristik emosional antara laki-laki dan perempuan yang berkembang dalam masyarakat. Fakih (2008) mengemukakan bahwa gender merupakan suatu sifat yang melekat pada kaum laki-laki maupun perempuan yang dikonstruksikan secara sosial maupun kultural. Hal ini yang kemudian membentuk paradigma tentang adanya perbedaan peran dan spesialisasi antara perempuan dan laki-laki dalam kehidupan bermasyarakat. Perbedaan juga terjadi dalam fungsi struktural dan kelembagaan dari sudut pandang gender melahirkan perjuangan yang menuntut adanya kesetaraan. Penelitian Kusumayanti (2014) mengenai Pengaruh Akuntabilitas, Pengetahuan Audit, dan Gender terhadap Kualitas Hasil Kerja Auditor Internal. Hasilnya menyatakan bahwa terdapat pengaruh positif dan signifikan antara gender terhadap kualitas hasil kerja audit internal.

Kinerja yaitu suatu hasil kerja yang dihasilkan oleh seorang karyawan diartikan untuk mencapai tujuan yang diharapkan. Mangkunegara (2010) kinerja adalah prestasi kerja atau hasil krja baik kualitas maupun kuantitas yang dicapai sumber daya manusia persatuan periode waktu dalam melaksanakan tugas kerjanya sesuai dengan tanggung jawab yang diberikan kepadanya. Kinerja karyawan merupakan suatu kemampuan seseorang dalam melaksanakan pekerjaannya dengan baik yang dipengaruhi oleh kemampuan, rasa tanggung jawab, disiplin kerja dalam mencapai tujuan organisasi dan hasil yang diharapkan. Untuk mengetahui seberapa baik kinerja karyawan, perlu dilakukan sebuah penilaian kinerja, yaitu proses yang dipakai 
oleh organisasi untuk mengevaluasi pelaksanaan kerja individu karyawan. Penilaian kinerja ini bertujuan untuk mengevaluasi (Evaluation) kinerja seorang pegawai, dan mengembangan (development) atau meningkatkan kinerja seorang pegawai (Simamora, 2006). Kinerja dapat dinilai dengan menggunakan metode skala rating yaitu dibawah rata-rata dan diatas rata-rata dengan melihat jumlah pekerjaan yang dilakukan atau dihasilkan dalam bentuk jabatan tertentu, dan kemampuan menangani tugas-tugas tertentu.

Usia yang muda seringkali disepelekan di dalam dunia kerja. Budaya senioritas kerap kali dijadikan alasan untuk menilai kinerja karyawan. Grade jabatan adalah tingkatan (level) penggolongan jabatan yang disusun berdasarkan berat ringannya tugas dan tanggung jawab jabatan-jabatan didalam organisasi di suatu perusahaan. Masing-masing grade jabatan terdiri dari jabatan-jabatan yang memiliki berat ringan tugas dan tanggung jawab jabatan yang relatif sama. Masingmasing grade jabatan memiliki persyaratan pendidikan dan pengalaman kerja tertentu bagi karyawan yang berhak menduduki jabatan-jabatan grade tersebut. Grade jabatan dalam organisasi terdiri dari grade 1 (terendah) sampai dengan grade 10 (tertinggi). Selanjutnya grade ini dibedakan dengan istilah senior dan junior (Kurnia, 2010).

Berdasarkan latar belakang permasalahan tersebut maka penelitian ini bertujuan untuk mengetahui determinan kinerja karyawan pada sektor pariwisata. Hipotesis dalam penelitian ini yaitu:

$\mathrm{H}_{1}$ : Gaya Kepemimpinan berpengaruh positif dan signifikan terhadap Kinerja Karyawan

$\mathrm{H}_{2}$ : Sistem Pengendalian Internal berpengaruh positif dan signifikan terhadap Kinerja Karyawan

$\mathrm{H}_{3}$ : Partisipasi Penyusunan Anggaran berpengaruh positif dan signifikan terhadap Kinerja Karyawan

$\mathrm{H}_{4}$ : Job Relevant Information berpengaruh positif dan signifikan terhadap Kinerja Karyawan

$\mathrm{H}_{5}$ : Motivasi berpengaruh positif dan signifikan terhadap Kinerja Karyawan
$\mathrm{H}_{6}$ : Budaya Organisasi berpengaruh positif dan signifikan terhadap Kinerja Karyawan

$\mathrm{H}_{7}$ : Gender berpengaruh positif dan signifikan terhadap Kinerja Karyawan

$\mathrm{H}_{8}$ : Grade Jabatan berpengaruh positif dan signifikan terhadap Kinerja Karyawan

$\mathrm{H}_{9}$ : Gaya Kepemimpinan, Sistem Pengendalian Internal, Partisipasi Penyusunan Anggaran, Job Relevant Information, Motivasi, Budaya Organisasi, Gender, dan Grade Jabatan berpengaruh secara simultan terhadap Kinerja Karyawan.

\section{METODE}

Penelitian ini dilakukan pada hotelhotel berbintang yang ada di Kawasan Lovina Kabupaten Buleleng Bali. Rancangan penelitian yang akan digunakan untuk menganalisis penelitian ini adalah tipe penelitian penjelasan. Hal ini dimaksudkan untuk menjelaskan hubungan kausal antara variabel-variabel melalui pengujian hipotesis yang telah dirumuskan. Penelitian ini menggunakan pendekatan kuantitatif. Data yang digunakan dalam penelitian ini adalah data primer. Data primer dalam penelitian ini diperoleh dengan menggunakan kuesioner atau daftar pertanyaan yang telah terstruktur dengan tujuan untuk mengumpulkan informasi dari karyawan. Rancangan penelitian ini akan berguna untuk menjawab rumusan masalah dalam penelitian dan juga menentukan tujuan penelitian yang ingin dicapai sehingga desain penelitian dari tahap awal hingga tahap pelaporan hasil penelitian.

Populasi dalam penelitian ini adalah karyawan bagian akuntansi pada hotelhotel berbintang di Kawasan Lovina. Teknik pengambilan sampel yang digunakan menggunakan metode purposive sampling, yaitu pengambilan sampel secara sengaja sesuai dengan persyaratan sampel atau kriteria tertentu yang diperlukan. Sampel pada penelitian ini berjumlah 13 Hotel Berbintang yang ada di Kawasan Lovina. 
Tabel 1. Sampel Penelitian

\begin{tabular}{|c|c|c|c|c|}
\hline No. & Nama Hotel & Alamat & $\begin{array}{c}\text { Jumlah } \\
\text { Karyawan } \\
\text { bagian } \\
\text { akuntansi }\end{array}$ & $\begin{array}{c}\text { Jumlah } \\
\text { Karyawan } \\
\text { Hotel }\end{array}$ \\
\hline 1. & Damai Hotel & $\begin{array}{l}\text { Jalan Damai Desa Kayu } \\
\text { Putih Melaka }\end{array}$ & 4 & 86 \\
\hline 2. & $\begin{array}{l}\text { Puri Bagus Lovina } \\
\text { Resort }\end{array}$ & $\begin{array}{l}\text { Jalan Seririt Singaraja } \\
\text { Desa Pemaron }\end{array}$ & 5 & 93 \\
\hline 3. & Aneka Lovina & Jalan Seririt Singaraja & 8 & 73 \\
\hline 4. & Puri Saron & $\begin{array}{l}\text { Jalan Seririt Singaraja } \\
\text { Desa Pemaron }\end{array}$ & 3 & 48 \\
\hline 5. & $\begin{array}{l}\text { Bali Paradise } \\
\text { Hotel }\end{array}$ & $\begin{array}{l}\text { Jalan Kartika Desa } \\
\text { Kalibukbuk }\end{array}$ & 3 & 55 \\
\hline 6. & Lovina Beach & Jalan Seririt Singaraja & 3 & 52 \\
\hline 7. & $\begin{array}{l}\text { Adirama Beach } \\
\text { Hotel }\end{array}$ & Jalan Seririt Singaraja & 3 & 80 \\
\hline 8. & Hotel melka & Jalan Seririt Singaraja & 3 & 100 \\
\hline 9. & The Lovina & Jalan Seririt Singaraja & 3 & 85 \\
\hline 10. & Bali Taman Hotel & Jalan Seririt Singaraja & 3 & 51 \\
\hline 11. & Aditya Hotel & Jalan Seririt Singaraja & 3 & 63 \\
\hline 12. & $\begin{array}{l}\text { Puri Mangga } \\
\text { Hotel }\end{array}$ & $\begin{array}{l}\text { Jalan Damai Desa Kayu } \\
\text { Putih Melaka }\end{array}$ & 3 & 48 \\
\hline 13. & $\begin{array}{r}\text { Lilin Lovina Beach } \\
\mathrm{Ju}\end{array}$ & $\begin{array}{l}\text { Jalan Seririt Singaraja } \\
\text { mlah }\end{array}$ & $\begin{array}{c}3 \\
47\end{array}$ & 46 \\
\hline
\end{tabular}

Metode analisis yang digunakan dalam penelitian ini adalah uji statistik deskriptif dan uji hipotesis dengan menggunakan regresi logistik. Penggunaan analisis regresi logistik adalah karena variabel dependen bersifat dikotomi. Model atau rumus regresi logistik yang digunakan untuk menguji hipotesis adalah sebagai berikut (Ghozali, 2011):

$Y=\operatorname{Ln}[p /(1-p)]=\beta_{0}+\beta_{1} X_{1}+\ldots \ldots \ldots+\beta_{n} X_{n}$

$\ln (K K / 1-K K)=b_{0}+b_{1} G P+b_{2} S P I+b_{3} P P A+b_{4} J R I+b_{5} M+b_{6} B O+b_{7} G D+b_{8} G J$

$\mathrm{Y}=$ Kinerja karyawan; variabel Dummy, $1=$ kinerja diatas rata-rata, $0=$ kinerja dibawah ratarata $(\mathrm{KK})$

$\mathrm{X}_{1}, . . \mathrm{n}=$ variabel bebas, dimana :

$\mathrm{X}_{1}=$ Gaya Kepemimpinan (GP)

$\mathrm{X}_{2}=$ Sistem Pengendalian Internal (SPI)

$\mathrm{X}_{3}=$ Partisipasi Penyusunan Anggaran (PPA)

$\mathrm{X}_{4}=$ Job Relevant Information (JRI)

$\mathrm{X}_{5}=$ Motivasi $(\mathrm{M})$

$\mathrm{X}_{6}=$ Budaya Organisasi $(\mathrm{BO})$

$\mathrm{X}_{7}=$ Gender (GD); variabel Dummy, $1=$ laki-laki, $0=$ Perempuan

$\mathrm{X}_{8}=$ Grade jabatan (GJ); variabel Dummy, $1=$ senior, $0=$ junior

$\beta_{0,1, n}=$ parameter model, dengan $n$ adalah klasifikasi masing-masing kategori variabel bebas.

Metode pengumpulan data dalam penelitian ini adalah dengan menggunakan kuesioner dengan empat item pertanyaan yang ditujukan ke karyawan bagian akuntansi. Pada penelitian ini, semua variabel diukur dengan menggunakan skala Likert 5 point, yaitu skor terendah 1 yang menyatakan sangat tidak setuju dan skor tertinggi 5 yang menyatakan sangat setuju. Pengujian kualitas terhadap data 
yang diperoleh dalam penelitian ini menggunakan uji validitas dan reliabilitas. Pengujian ini bertujuan untuk mengetahui apakah instrumen yang digunakan valid dan reliable. Pengujian validitas dilakukan dengan mengkorelasikan setiap item-item pertanyaan dengan total nilai setiap variabel. Korelasi setiap item pertanyaan dengan nilai total setiap variabel dilakukan dengan teknik korelasi yaitu korelasi bivariate (pearson correlation) antara masing-masing skor indikator dengan total skor indikator untuk mengetahui apakah variabel yang diuji valid atau tidak (Ghozali, 2011). Dasar pengambilan keputusannya adalah jika korelasi antara masing-masing indikator terhadap total skor konstruk menunjukkan hasil yang signifikan dan lebih besar dari 5\%, jadi dapat disimpulkan bahwa masing-masing indikator pertanyaan adalah valid. Untuk pengukuran reabilitas, SPPS memberikan fasilitas untuk mengukur reliabilitas dengan uji statistik Cronbach Alpha. Suatu variabel dikatakan reliabel jika memberikan nilai Cronbach Alpha > 0,70 (Nunnally, 1967 dalam Ghozali, 2011)

Analisis pengujian dengan regresi logistik menurut Santoso (2004) memperhatikan hal-hal berikut :

1. Menilai kelayakan model regresi (Goodness of fit test)

Dengan memperhatikan output dari Hosmer dan Lemeshow dengan hipotesis yaitu:

$\mathrm{H}_{0}=$ tidak ada perbedaan nyata antara klasifikasi yang diprediksi dengan klasifikasi yang diamati

$\mathrm{Ha}=$ ada perbedaan nyata antara klasifikasi yang diprediksi dengan klasifikasi yang diamati

Dasar pengambilan keputusan yaitu dengan memperhatikan nilai I yang diukur dengan nilai chisquare pada bagian bawah uji Hosmer dan Lemeshow :

a.Jika probabilitas $>0,05, \mathrm{H}_{0}$ diterima

b. Jika probabilitas $<0,05, \mathrm{H}_{0}$ ditolak

2. Menilai Keseluruhan Model (Overall Model Fit)

Memperhatikan angka -2 log likelihood (LL) pada awal (block number = 0) dan angka -2 log likelihood pada blocknumber $=1$. Jika terjadi penurunan angka -2 log likelihood block number 0 - block number 1 menunjukkan model regresi yang baik.

3. Model Summary

Model summary dalam regresi logistik sama dengan pengujian $\mathrm{R}^{2}$ pada persamaan regresi linear. Tujuan dari model summary adalah untuk mengetahui seberapa besar kombinasi variabel independen yang terdiri dari Gaya Kepemimpinan, Sistem Pengendalian Internal, Partisipasi Penyusunan Anggaran, Job Relevant Information, Motivasi, Budaya Organisasi, Gender dan Grade jabatan mampu menjelaskan variabel dependen yaitu Kinerja Karyawan.

4. Pengujian Individual/ Pengujian koefisien Regresi

Uji koefisien regresi pada dasarnya menunjukan seberapa jauh pengaruh suatu variabel independen secara individual dalam menerangkan variasi variabel dependen (Ghozali, 2006). Dalam hal ini, apakah variabel Gaya Kepemimpinan, Sistem Pengendalian Internal, Partisipasi Penyusunan Anggaran, Job Relevant Information, Motivasi, Budaya Organisasi, Gender dan Grade jabatan benar-benar berpengaruh terhadap kinerja karyawan. Dalam pengujian koefisien regresi perlu memperhatikan beberapa hal sebagai berikut :

a. Tingkat signifikasi $(\alpha)$ yang digunakan sebesar 5 persen $(0,05)$.

b. Kriteria penerimaan dan penolakan hipotesis didasarkan pada signifikansi $p$-value (probabilitas value). Jika $p$-value $>\alpha$, maka hipotesis alternatif ditolak, sebaliknya jika $p$-value < a maka hipotesis alternatif diterima.

5. Omnibus Test of Model Coefficient (Pengujian Simultan)

Pengujian ini dilakukan untuk 
menguji pengaruh dari variabelvariabel independen secara serentak terhadap variabel dependennya yaitu Kinerja Karyawan.

Ho: $\beta 1=\beta 2=\beta 3=\beta 4=\beta 5=\beta 6=\beta 7=0$ : Gaya Kepemimpinan, Sistem Pengendalian Internal, Partisipasi Penyusunan Anggaran, Job Relevant Information, Motivasi, Budaya Organisasi, Gender dan Grade Jabatan secara bersamasama tidak berpengaruh terhadap Kinerja Karyawan.

$\mathrm{Ha}: \quad \beta 1 \neq \beta 2 \neq \beta 3 \neq \beta 4 \neq \beta 5 \neq \beta 6 \neq \beta 7=0$ : Gaya Kepemimpinan, Sistem
Pengendalian Internal, Partisipasi Penyusunan Anggaran, Job Relevant Information, Motivasi, Budaya Organisasi, Gender dan Grade Jabatan secara bersamasama berpengaruh terhadap Kinerja Karyawan.

\section{HASIL DAN PEMBAHASAN}

Responden dalam penelitian ini adalah karyawan hotel. Karyawan yang dijadikan responden dalam penelitian ini adalah karyawan bagian akuntansi.

Tabel 2. Rincian Kuesioner

\begin{tabular}{llccccc}
\hline No & \multicolumn{1}{c}{ Hotel } & $\begin{array}{c}\text { Kuesioner } \\
\text { Disebar }\end{array}$ & $\begin{array}{c}\text { Kuesioner } \\
\text { Kembali }\end{array}$ & $\begin{array}{c}\text { Persentase } \\
\text { Pengembalian } \\
\text { Kuesioner }\end{array}$ & $\begin{array}{c}\text { Kuesioner } \\
\text { Gugur }\end{array}$ & $\begin{array}{c}\text { Kuesioner } \\
\text { Diolah }\end{array}$ \\
\hline 1 & Damai Hotel & 4 & 4 & $100 \%$ & - & 4 \\
\hline 2 & $\begin{array}{l}\text { Puri Bagus } \\
\text { Lovina Resort }\end{array}$ & 5 & 5 & $100 \%$ & - & 5 \\
\hline 3 & Aneka Lovina & 8 & 8 & $100 \%$ & - & 3 \\
\hline 4 & Puri Saron & 3 & 3 & $100 \%$ & - & 3 \\
\hline 5 & $\begin{array}{l}\text { Bali Paradise } \\
\text { Hotel }\end{array}$ & 3 & 3 & $100 \%$ & - & 3 \\
\hline 6 & Lovina Beach & 3 & 3 & $100 \%$ & 3 \\
\hline 7 & $\begin{array}{l}\text { Adirama } \\
\text { Beach Hotel }\end{array}$ & 3 & 3 & $100 \%$ & 3 \\
\hline 8 & Hotel melka & 3 & 3 & $100 \%$ & - & 3 \\
\hline 9 & The Lovina & 3 & 3 & $100 \%$ & - & 3 \\
\hline 10 & $\begin{array}{l}\text { Bali Taman } \\
\text { Hotel }\end{array}$ & 3 & 3 & $100 \%$ & - & 3 \\
\hline 11 & Aditya Hotel & 3 & 3 & $100 \%$ & - & 3 \\
\hline 12 & $\begin{array}{l}\text { Puri Mangga } \\
\text { Hotel }\end{array}$ & 3 & 3 & $100 \%$ & $\mathbf{4 7}$ \\
\hline 13 & $\begin{array}{l}\text { Lilin Lovina } \\
\text { Beach }\end{array}$ & 3 & 3 & $100 \%$ & - & 3 \\
\hline & Jumlah & $\mathbf{4 7}$ & $\mathbf{4 7}$ & $\mathbf{1 0 0 \%}$ & - & 3 \\
\hline Sumber & & & & - & 3 \\
\hline
\end{tabular}

Sumber: data diolah

Tabel 3. Gambaran Umum Responden

\begin{tabular}{lcc}
\hline \multicolumn{1}{c}{ Hotel } & Laki- laki & Perempuan \\
\hline Damai Hotel & 2 & 2 \\
\hline Puri Bagus Lovina Resort & 3 & 2 \\
\hline Aneka Lovina & 5 & 3 \\
\hline Puri Saron & 2 & 1 \\
\hline Bali Paradise Hotel & 3 & - \\
\hline Lovina Beach & 1 & 2 \\
\hline Adirama Beach Hotel & 2 & 1 \\
\hline Hotel melka & 1 & 2 \\
\hline The Lovina & 3 & - \\
\hline Bali Taman Hotel & 2 & 1 \\
\hline
\end{tabular}




\begin{tabular}{rcc}
\hline Hotel & Laki- laki & Perempuan \\
\hline Aditya Hotel & 1 & 2 \\
\hline Puri Mangga Hotel & 2 & 1 \\
\hline Lilin Lovina Beach & 2 & 1 \\
\hline Jumlah & $\mathbf{2 9}$ & $\mathbf{1 8}$ \\
\hline
\end{tabular}

Sumber: data primer diolah

Uji validitas dalam penelitian ini dilakukan dengan menggunakan Pearson's Correlation Product Moment dengan bantuan program SPSS 19.0 for Windows.

Butir pertanyaan mengenai Gaya Kepemimpinan memiliki tingkat korelasi sebesar $\quad 0,689-0,799, \quad$ Sistem Pengendalian Internal memiliki tingkat korelasi sebesar 0,750-0,755, Partisipasi Penyusunan Anggaran memiliki tingkat korelasi sebesar 0,751-0,771, Job Relevant Information memiliki tingkat korelasi sebesar 0,675-0,807, Motivasi memiliki tingkat korelasi sebesar 0,6160,454 , Budaya Organisasi memiliki tingkat korelasi sebesar 0,573-0,617.
Kriteria valid atau tidaknya kuesioner dinyatakan apabila nilai $r$ yang diperoleh dari hasil perhitungan $r_{\text {hitung product }}$ moment $>$ dari nilai $r_{\text {tabel }}$ product moment dengan tarif signifikan $5 \%$ maka butir-butir pertanyaan kuesioner adalah valid. Hasil pengujian validitas pertanyaanpertanyaan pada kuesioner menunjukkan korelasi positif pada level 0,000-0,007 atau dibawah 0,05 dan terpenuhinya $r_{\text {hitung }}$ product moment $>$ dari nilai $r_{\text {tabel }}$ product moment yang dapat dilihat pada Sig. (2tailed). Jumlah data $(n)=47$, maka diperoleh $r_{\text {tabel }}$ sebesar 0,2483. Berdasarkan output, nilai korelasi untuk semua item lebih besar dari $r_{\text {tabel }}$ sehingga seluruh item pertanyaan dinyatakan valid.

Tabel 4. Hasil Uji Validitas

\begin{tabular}{clccc}
\hline No. & \multicolumn{1}{c}{ Variabel/Pernyataan } & $\begin{array}{c}\text { Pearson } \\
\text { Correlation }\end{array}$ & $\begin{array}{c}\text { Sig. (2- } \\
\text { tailed) }\end{array}$ & Keterangan \\
\hline & Gaya Kepemimpinan & & & \\
\hline 1. & Pernyataan 1 & 0,689 & 0,000 & Valid \\
\hline 2. & Pernyataan 2 & 0,655 & 0,000 & Valid \\
\hline 3. & Pernyataan 3 & 0,777 & 0,000 & Valid \\
\hline 4. & Pernyataan 4 & 0,710 & 0,000 & Valid \\
\hline 5. & Pernyataan 5 & 0,799 & 0,000 & Valid \\
\hline & Sistem Pengendalian Internal & & & \\
\hline 1. & Pernyataan 1 & 0,750 & 0,000 & Valid \\
\hline 2. & Pernyataan 2 & 0,725 & 0,000 & Valid \\
\hline 3. & Pernyataan 3 & 0,815 & 0,000 & Valid \\
\hline 4. & Pernyataan 4 & 0,720 & 0,000 & Valid \\
\hline 5. & Pernyataan 5 & 0,589 & 0,000 & Valid \\
\hline 6. & Pernyataan 6 & 0,755 & 0,000 & Valid \\
\hline & Partisipasi Penyusunan Anggaran & & & \\
\hline 1. & Pernyataan 1 & 0,751 & 0,000 & Valid \\
\hline 2. & Pernyataan 2 & 0,710 & 0,000 & Valid \\
\hline 3. & Pernyataan 3 & 0,819 & 0,000 & Valid \\
\hline 4. & Pernyataan 4 & 0,772 & 0,000 & Valid \\
\hline 5. & Pernyataan 5 & 0,595 & 0,000 & Valid \\
\hline 6. & Pernyataan 6 & 0,771 & 0,000 & Valid \\
\hline & Job Relevant Information & & & \\
\hline 1. & Pernyataan 1 & 0,675 & 0,000 & Valid \\
\hline 2. & Pernyataan 2 & 0,635 & 0,000 & Valid \\
\hline 3. & Pernyataan 3 & 0,763 & 0,000 & Valid \\
\hline 4. & Pernyataan 4 & 0,701 & 0,000 & Valid \\
\hline & & & & \\
\hline
\end{tabular}


Vol. 5, No.2, Oktober 2016

\begin{tabular}{|c|c|c|c|c|}
\hline No. & Variabel/Pernyataan & $\begin{array}{c}\text { Pearson } \\
\text { Correlation }\end{array}$ & $\begin{array}{l}\text { Sig. (2- } \\
\text { tailed) }\end{array}$ & Keterangan \\
\hline 5. & Pernyataan 5 & 0,807 & 0,000 & Valid \\
\hline & \multicolumn{4}{|l|}{ Motivasi } \\
\hline 1. & Pernyataan 1 & 0,616 & 0,000 & Valid \\
\hline 2. & Pernyataan 2 & 0,573 & 0,000 & Valid \\
\hline 3. & Pernyataan 3 & 0,620 & 0,000 & Valid \\
\hline 4. & Pernyataan 4 & 0,660 & 0,000 & Valid \\
\hline 5. & Pernyataan 5 & 0,526 & 0,000 & Valid \\
\hline 6. & Pernyataan 6 & 0,454 & 0,001 & Valid \\
\hline & \multicolumn{4}{|l|}{ Budaya Organisasi } \\
\hline 1. & Pernyataan 1 & 0,573 & 0,000 & Valid \\
\hline 2. & Pernyataan 2 & 0,557 & 0,000 & Valid \\
\hline 3. & Pernyataan 3 & 0,496 & 0,000 & Valid \\
\hline 4. & Pernyataan 4 & 0,486 & 0,001 & Valid \\
\hline 5. & Pernyataan 5 & 0,396 & 0,007 & Valid \\
\hline 6. & Pernyataan 6 & 0,617 & 0,000 & Valid \\
\hline
\end{tabular}

Sumber: output SPSS, data diolah.

Pengujian reliabilitas dengan uji statistik Cronbach Alpha. Suatu variabel dikatakan reliabel jika memberikan nilai Cronbach Alpha $>0,70$

Tabel 5. Hasil Pengujian Reliabilitas

\begin{tabular}{lcc}
\hline \multicolumn{1}{c}{ Variabel } & Cronbach's Alpha & Keterangan \\
\hline Gaya Kepemimpinan $\left(\mathrm{X}_{1}\right)$ & 0,775 & Reliabel \\
\hline Sistem Pengendalian Internal $\left(\mathrm{X}_{2}\right)$ & 0,815 & Reliabel \\
\hline Partisipasi Penyusunan Anggaran $\left(\mathrm{X}_{3}\right)$ & 0,827 & Reliabel \\
\hline Job Relevant Information $\left(\mathrm{X}_{4}\right)$ & 0,762 & Reliabel \\
\hline Motivasi $\left(\mathrm{X}_{5}\right)$ & 0,821 & Reliabel \\
\hline Budaya Organisasi $\left(\mathrm{X}_{6}\right)$ & 0,820 & Reliabel \\
\hline Sumber: Data Primer Diolah, 2016 & &
\end{tabular}

Pengujian hipotesis menggunakan model logistic regression binary dengan metode enter pada tingkat signifikan $(\alpha)$ $5 \%$. logistic regression binary digunakan untuk menguji pengaruh Gaya Kepemimpinan, Sistem Pengendalian Internal, Partisipasi Penyusunan Anggaran, Job Relevant Information, Motivasi, Budaya Organisasi, Gender dan Grade jabatan terhadap Kinerja Karyawan. Hasil pengujian hipotesis yaitu:

1) Menilai kelayakan model regresi (goodness of fit test) Model fit dapat diuji dengan Hosmer and Lemeshow Test. Hasil output SPSS pada tabel 4 menunjukkan bahwa nilai Hosmer and Lemeshow sebesar 6,794 dan nilai profitabilitas signifikansi 0,451 dengan nilai signifikansi yang lebih besar dari 0,05 maka diperoleh tidak adanya perbedaan yang nyata antara klasifikasi yang diprediksi dengan klasifikasi yang diamati. Sehingga model regresi yang dipergunakan dalam penelitian ini layak dipakai untuk analisis selanjutnya.

Tabel 6. Hosmer and Lemeshow Test

\begin{tabular}{|l|r|r|r|}
\hline Step & Chi-square & df & Sig. \\
\hline 1 &, 000 & 0 & \\
\hline 2 & 6,794 & 7 &, 451 \\
\hline \multicolumn{4}{|c|}{ Sumber: data output SPSS } \\
\hline
\end{tabular}


2) Menilai keseluruhan model (Overall Model Fit)

Menilai model fit dapat dilihat dari nilai statistik -2LogL yaitu tanpa variabel hanya konstanta saja sebesar 53,402 setelah dimasukkan variabel baru maka nilai -2LogL turun menjadi 23,782 atau terjadi penurunan sebesar 29,620. Penurunan ini signifikan atau tidak dapat dibandingkan antara tabel dengan df1 $=(n-k)=47-8=39$ jadi selisih $d f=47-39=8$. Dari tabel dengan $\mathrm{df}=8$ didapat angka 2,306. Oleh karena 29,620 lebih besar dari tabel maka dapat dikatakan bahwa selisih penurunan -2Log L signifikan. Penurunan Likelihood ini menunjukkan model regresi yang lebih baik atau dengan kata lain model yang dihipotesiskan fit dengan data.

Tabel 7. Overall model fit test

\begin{tabular}{|c|c|c|}
\hline \multirow{3}{*}{ Iteration } & \multirow{3}{*}{$\begin{array}{l}-2 \text { Log } \\
\text { likelihood }\end{array}$} & Coefficient \\
\hline & & \\
\hline & & Constant \\
\hline \multirow{4}{*}{ Step 0} & 53,478 & ,979 \\
\hline & 53,402 & 1,069 \\
\hline & 53,402 & 1,070 \\
\hline & 53,402 & 1,070 \\
\hline
\end{tabular}

a. Constant is included in the model.

b. Initial -2 Log Likelihood: 53,402

c. Estimation terminated at iteration number 4 because parameter estimates changed by less than, 001 .

Sumber: output SPSS

3) Model Summary $\left(R^{2}\right)$

Dari hasil output SPSS memberikan nilai Cox \& Snell $R$ Square sebesar 0,468 dan nilai Nagelkerke $R$ Square adalah 0,689.
Artinya
variabilitas variabel dependen (KK) yang dapat dijelaskan oleh variabilitas variabel independen yaitu GP, SPI, PPA, JRI, M, BO, GD, GJ sebesar $68,9 \%$

Tabel 8. Model Summary

\begin{tabular}{|l|r|r|r|}
\hline Step & $\begin{array}{c}-2 \text { Log } \\
\text { likelihood }\end{array}$ & $\begin{array}{c}\text { Cox \& Snell } \\
\text { R Square }\end{array}$ & $\begin{array}{c}\text { Nagelkerke } \\
\text { R Square }\end{array}$ \\
\hline 1 & $30,843^{\mathrm{a}}$ &, 381 &, 561 \\
2 & $23,782^{\mathrm{a}}$ &, 468 &, 689 \\
\hline
\end{tabular}

a. Estimation terminated at iteration number 6 because parameter estimates changed by less than ,001.

Sumber: output SPSS

4) Menguji Koefisien Regresi secara Parsial

Tabel 9 menunjukkan hasil pengujian dengan regresi logistik pada tingkat signifikan 0,05 . 
Tabel 9. Hasil Regresi Logistik

Variables in the Equation

\begin{tabular}{|rl|r|r|r|r|r|r|}
\hline & & \multicolumn{1}{|c|}{ B } & \multicolumn{1}{|c|}{ S.E. } & \multicolumn{1}{c|}{ Wald } & \multicolumn{1}{c|}{ df } & \multicolumn{1}{c|}{ Sig. } & \multicolumn{1}{c|}{ Exp(B) } \\
\hline \multirow{2}{*}{ Step 1 ${ }^{\text {a }}$ GP } & 3,973 & 1,137 & 12,219 & 1 &, 000 & 53,167 \\
& SPI &, 606 &, 508 & 1,426 & 1 &, 032 & 1,545 \\
& PPA &, 588 &, 280 & 4,417 & 1 &, 026 &, 555 \\
JRI &, 294 &, 682 & 3,600 & 1 &, 013 & 4,333 \\
M &, 413 &, 783 & 4,118 & 1 &, 029 & 1,588 \\
BO & 1,003 & 1,197 &, 296 & 1 &, 042 &, 521 \\
GD &, 535 &, 586 &, 663 & 1 &, 000 & 1,000 \\
GJ &, 713 &, 058 &, 553 & 1 &, 000 & 1,000 \\
Constant & $-5,243$ & 5,605 & 4,024 & 1 &, 045 & 754,579 \\
\hline
\end{tabular}

a. Variable(s) entered on step 1: GP, SPI, PPA, JRI, M, BO, GD, GJ

\section{Sumber: Output SPSS}

Dari pengujian persamaan regresi logistik tersebut maka diperoleh model regresi logistik sebagai berikut:

$\begin{aligned} \operatorname{Ln}(\mathrm{KK} / 1-\mathrm{KK})= & -5,243+3,973 \mathrm{GP}+ \\ & 0,606 \mathrm{SPI}+0,588 \mathrm{PPA}+ \\ & 0,294 \mathrm{JRI}+0,413 \mathrm{M}+ \\ & 1,003 \mathrm{BO}+0,535 \mathrm{GD}+ \\ & 0,713 \mathrm{GJ}\end{aligned}$

atau

KK/1-KK = e

5,243+3,973GP+0,606SPI+0,588PPA+0,294JRI+0,413M+1,003B $\mathrm{O}+0,535 \mathrm{GD}+0,713 \mathrm{GJ}$

Variabel GP, SPI, PPA, JRI, M, BO, GD, GJ signifikan pada 0,05. Dari persamaan logistic regression dapat dilihat bahwa log Kinerja Karyawan (KK) mempunyai kinerja di atas rata-rata secara positif dipengaruhi oleh GP, SPI, PPA, JRI, $M, B O, G D, G J$. Jika variabel SPI, PPA, JRI, M, BO, GD, GJ dianggap konstan, maka KK akan mempunyai kinerja diatas rata-rata dengan faktor $\left(\mathrm{e}^{3,973}\right)$ untuk setiap kenaikan GP. Begitu juga jika GP, PPA, $\mathrm{JRI}, \mathrm{M}, \mathrm{BO}, \mathrm{GD}$, GJ dianggap konstan, maka KK akan mempunyai kinerja diatas rata-rata dengan faktor $\left(\mathrm{e}^{0,606}\right)$ untuk setiap kenaikan SPI. Jika GP, SPI, JRI, M, BO, GD, GJ dianggap konstan, maka KK akan mempunyai kinerja diatas rata-rata dengan faktor $\left(\mathrm{e}^{0,588}\right)$ untuk setiap kenaikan PPA. Jika GP, SPI, PPA, M, BO, GD, GJ dianggap konstan, maka $\mathrm{KK}$ akan mempunyai kinerja diatas rata-rata dengan faktor $\left(\mathrm{e}^{0,294}\right)$ untuk setiap kenaikan JRI. Jika GP, SPI, PPA, JRI, BO, GD, GJ dianggap konstan, maka KK akan mempunyai kinerja diatas rata-rata dengan faktor $\left(\mathrm{e}^{0,413}\right)$ untuk setiap kenaikan M. Jika GP, SPI, PPA, JRI, M, GD, GJ dianggap konstan, maka KK akan mempunyai kinerja diatas rata-rata dengan faktor $\left(\mathrm{e}^{1,003}\right)$ untuk setiap kenaikan BO. Jika GP, SPI, PPA, JRI, M, BO, GJ dianggap konstan, maka $\mathrm{KK}$ akan mempunyai kinerja diatas ratarata dengan faktor $\left(e^{0,535}\right)$ untuk setiap kenaikan GD. Jika GP, SPI, PPA, JRI, M, $\mathrm{BO}, \mathrm{GD}$ dianggap konstan, maka KK akan mempunyai kinerja diatas rata-rata dengan faktor $\left(\mathrm{e}^{0,713}\right)$ untuk setiap kenaikan GJ.

$$
\text { Hasil pengujian parsial }
$$

menunjukkan bahwa variabel GP, SPI, PPA, JRI, M, BO, GD, GJ memiliki nilai signifikansi $<0,005$. Koefisien regresi logistik untuk variabel GP, SPI, PPA, JRI, $\mathrm{M}, \mathrm{BO}, \mathrm{GD}, \mathrm{GJ}$ positif dari hasil tersebut maka $\mathrm{H}_{1}$ yang menyatakan bahwa Gaya Kepemimpinan berpengaruh positif dan signifikan terhadap Kinerja Karyawan adalah diterima. $\mathrm{H}_{2}$ yang menyatakan bahwa Sistem Pengendalian Internal berpengaruh positif dan signifikan terhadap Kinerja Karyawan adalah diterima. $\mathrm{H}_{3}$ yang menyatakan bahwa Partisipasi Penyusunan Anggaran berpengaruh positif dan signifikan terhadap Kinerja Karyawan adalah diterima. $\mathrm{H}_{4}$ yang menyatakan bahwa Job Relevant Information berpengaruh positif dan signifikan terhadap Kinerja Karyawan adalah diterima. $\mathrm{H}_{5}$ yang menyatakan bahwa Motivasi berpengaruh positif dan signifikan terhadap Kinerja Karyawan adalah diterima. $\mathrm{H}_{6}$ yang menyatakan bahwa Budaya Organisasi berpengaruh positif dan signifikan terhadap 
Kinerja Karyawan adalah diterima. $\mathrm{H}_{7}$ yang menyatakan bahwa Gender berpengaruh positif dan signifikan terhadap Kinerja Karyawan adalah diterima. $\mathrm{H}_{8}$ yang menyatakan bahwa Grade Jabatan berpengaruh positif dan signifikan terhadap Kinerja Karyawan adalah diterima.

Dari hasil pengujian regresi logistik untuk Omnibus Tests of Model Coefficients diperoleh hasil yaitu Chi-square 46,782, degree of freedom 8 dan tingkat signifikansi $0,000<0,05$. Maka Ha diterima yaitu variabel GP, SPI, PPA, JRI, M, BO, GD, GJ secara bersama-sama berpengaruh terhadap variabel $\mathrm{KK}$.

Tabel 10. Omnibus Test of Model Coefficients

\begin{tabular}{|c|c|c|c|c|}
\hline & Chi-square & $\mathrm{df}$ & Sig. \\
\hline & Step & 46,782 & 8 & ,000 \\
\hline \multirow{2}{*}{ Step 1} & Bloc & 46,782 & 8 & ,000 \\
\hline & Model & 46,782 & 8 &, 000 \\
\hline
\end{tabular}

Sumber: data output SPSS

Gaya kepemimpinan merupakan suatu cara seorang pemimpin didalam organisasi untuk mempengaruhi bawahannya agar dapat melakukan kegiatan yang dapat tercapainya tujuan. Seorang pemimpin harus memperhatikan bawahannya supaya merasa nyaman ketika bekerja. Dengan kenyamanan yang dirasakan oleh karyawan ketika bekerja maka akan berdampak kepada peningkatan kinerja karyawan dalam melaksanakan tugasnya. Penelitian ini sejalan dengan penelitian Yunista (2013) dan Sari (2013)

Sistem Pengendalian Internal yang handal dan efektif dapat memberikan informasi yang tepat bagi manajer maupun dewan direksi dalam pengambilan keputusan maupun kebijakan untuk pencapaian tujuan perusahaan yang lebih efektif pula. Tercapainya pengendalian internal perusahaan yang baik tentu saja akan meningkatkan produktivitas serta kinerja para karyawan pada suatu perusahan. Penelitian ini sejalan dengan penelitian Usman (2013).

Partisipasi penyusunan anggaran merupakan keterlibatan seluruh manajer dari lini menengah ke bawah dalam suatu instansi untuk melakukan kegiatan dalam pencapaian sasaran yang ditetapkan dalam anggaran. Dengan adanya keterlibatan tersebut maka akan mendorong para manajer dan kepala bagian untuk bertanggung jawab terhadap masing-masing tugas yang diembannya sehingga akan meningkatkan kinerja mereka agar mencapai sasaran yang telah ditetapkan dalam anggaran. Hasil penelitian ini sejalan dengan penelitian Widanarta (2003) dan Mattola (2011). Job relevant information menunjukkan peran informasi dalam memudahkan pembuatan keputusan yang berhubungan dengan jabatan informasi yang diberikan manajer dalam penyusunan anggaran akan meningkatkan kemampuan individual terhadap kinerja. Hal ini karena adanya partisipasi manajer tingkat bawah memiliki kesempatan untuk memberikan informasi yang mereka miliki untuk membantu dalam pembuatan keputusan. Sehingga dengan adanya informasi yang relevan dengan tugas maka tujuan yang diharapkan akan tercapai. Hasil penelitian ini sejalan dengan penelitian Putra (2014).

Motivasi merupakan kondisi yang menggerakan diri pegawai yang terarah untuk mencapai tujuan organisasi (tujuan kerja). Sikap mental merupakan kondisi mental yang mendorong diri pegawai untuk berusaha mencapai prestasi kerja secara maksimal. Hasil penelitian ini sejalan dengan penelitian Ismuhadjar (2006) dan Windayani (2013).

Peran budaya organisasi adalah sebagai sarana untuk menentukan arah organisasi, mengarahkan apa yang patut dan tidak patut dikerjakan, bagaimana mengalokasikan sumber daya organisasi (Pramastuti, 2006). Budaya organsasi menjadi faktor yang sangat penting dalam menentukan keberhasilan atau kegagalan organisasi di masa mendatang. Budaya yang merosot akan berdampak negatif terhadap kinerja organisasi. Walaupun budaya relatif sulit berubah, tetapi budaya 
organisasi dapat dibuat agar lebih meningkatkan kinerja. Hasil penelitian ini sejalan dengan penelitian Koesmono (2005) menyatakan bahwa budaya organisasi berpengaruh positif terhadap kinerja pegawai.

Pengambilan keputusan harus didukung oleh informasi yang memadai. Kaum pria dalam pengolahan informasi tersebut biasanya tidak menggunakan seluruh informasi yang tersedia sehingga keputusan yang diambil kurang komprehensif. Lain halnya dengan wanita, mereka dalam mengolah informasi cenderung lebih teliti dengan menggunakan informasi yang lebih lengkap dan mengevaluasi kembali informasi tersebut dan tidak gampang menyerah (Meyer dan Levy, 1986). Kaum wanita relatif lebih efisien dibandingkan kaum pria selagi mendapat akses informasi. Selain itu, kaum wanita juga memiliki daya ingat yang lebih tajam terhadap suatu informasi baru dibandingkan kaum pria dan demikian halnya kemampuan dalam mengolah informasi yang sedikit menjadi lebih tajam. Hasil penelitian ini sejalan dengan penelitian Kusumayanti (2014).

Grade jabatan adalah tingkatan penggolongan jabatan yang disusun berdasarkan berat ringannya tugas dan tanggung jawab jabatan-jabatan didalam organisasi di suatu perusahaan. Masingmasing grade jabatan terdiri dari jabatanjabatan yang memiliki berat ringan tugas dan tanggung jawab jabatan yang relatif sama. Sehingga dengan pengembangan karir yang lebih terarah terbukti mampu meningkatkan motivasi kerja dan kinerja karyawan. Penelitian ini sejalan dengan penelitian Dany, dkk (2014).

\section{SIMPULAN DAN SARAN}

Berdasarkan hasil penelitian diatas maka dapat diambil kesimpulan bahwa variabel Gaya Kepemimpinan, Sistem Pengendalian Internal, Partisipasi Penyusunan Anggaran, Job Relevant Information, Motivasi, Budaya Organisasi, Gender dan Grade Jabatan berpengaruh positif dan signifikan terhadap Kinerja Karyawan.

Peneliti menyarankan yaitu: Hotelhotel berbintang yang ada di kawasan
Lovina sudah memperhatikan segala aspek yang mendukung dalam peningkatan kinerja karyawan, sehingga untuk selanjutnya dengan memperhatikan aspek-aspek kesejahteraan karyawan dapat meningkatkan pelayanan kepada wisatawan yang datang. Untuk peneliti selanjutnya dapat memperluas sampel penelitian yaitu hotel-hotel berbintang yang ada di Provinsi Bali sehingga dapat meningkatkan validitas hasil penelitian.

\section{DAFTAR PUSTAKA}

Antari, N, L, S. 2013. Peran Industri Pariwisata Terhadap Penerimaan Pendapatan Asli Daerah Kabupaten Gianyar. Jurnal Perhotelan dan Pariwisata 3 (1): 35-45.

Bastian, I. 2009. Akuntansi Sektor Publik Di Indonesia. Yogyakarta: BPFE

Dany, A, I., Pranayoga, O., Kurniawan, A., \& Adrianto, A, S. 2014. Hubungan Jenjang Karir Terhadap Kinerja Karyawan (Korelasi Antara Pengembangan Karir dengan Motivasi Kerja dan Keinginan Pensiun Dini. Laporan Jurusan IImu Administrasi Universitas Brawijaya.

Daryatmi. 2005. Pengaruh Motivasi, Pengawasan Dan Budaya Kerja Terhadap Produktivitas Kerja Karyawan Perusahaan Daerah Bank Perkreditan Rakyat Badan Kredit Desa Kabupaten Karanganyar. Artikel.

Dinas Pendapatan Pemerintah kabupaten Buleleng. 2014. Laporan Realisasi Penerimaan Anggaran Pendapatan Daerah.

Ghozali, I. 2011. Aplikasi Analisis Multivariate dengan Program IMB SPSS 19. Edisi 5. Semarang: Badan Penerbit Universitas Diponegoro.

Hafizurrachman H, M. 2007. Pengaruh Gaya Kepemimpinan Atasan, Lingkungan Kerja, dan Motivasi Kerja terhadap Kinerja Kepala Program Studi Kesehatan dan Kedokteran Pada Perguruan Tinggi Swasta Wilayah Kopertis III. Disertasi. Jakarta: Uiversitas Negeri Jakarta.

Hasibuan, M, S, P. 2008. Manajemen Sumber Daya Manusia. Jakarta: PT. Bumi Aksara. 
Hersey, P, B., \& Johnson, D. 2001. Management of Organizational Behavior; Leading Human Resources, $8^{\text {th }}$ Edition, New Jersey: Prentice Hall.

Hofstede, G., Bram, N., Denise, D.O., \& Geert, S. 1990. Measuring Organizational Culture: A Qualitative and Quantitative Study across Twenty Cases. Administrative Science Quarterly. (35): 286-316.

Ismuhadjar. 2006. Pengaruh Motivasi Kerja, Komunikasi Antar Pribadi dan KomitmenOrganisasi terhadap Kinerja Pejabat Struktural dan Dosen Tetap di Beberapa Perguruan Tinggi Swasta di Jakarta. Jurnal Bisnis Strategi 15 (2): 52- 61.

Koesmono, H, T. 2005. Pengaruh Budaya Organisasi Terhadap Motivasi dan Kepuasan Kerja Serta Kinerja Karyawan Pada Sub Sektor Industri Pengolahan Kayu Ekspor di Jawa Timur. Disertasi Universitas Airlangga Surabaya.

Kurnia, $\quad$ http://www.google.com. Adilkurnia.com/2010/03/07/Sistem.K arir.Karyawan/. diakses tanggal 12 Februari 2016.

Mangkunegara, A, A. \& Prabu, A. 2002. Manajemen Sumber Daya Manusia Perusahaan. Bandung: PT. Remaja Rosdakarya.

Mattola, R. 2011. Pengaruh Partisipasi Anggaran Terhadap Kinerja Dengan Locus Of Control Sebagai Variabel Moderating (Studi Kasus Pada PT. Kimia Farma Trading \& Distribution Cabang Makasar). Skripsi. Fakultas Ekonomi, Universitas Hasanuddin.

Mulyanto, D, W. 2011. Pengaruh Kepemimpinan Dan Motivasi Kerja Terhadap Kinerja Pegawai Dengan Kepuasan Kerja Sebagai Variabel Moderating. STIE AUB Surakarta. I (1): 1-18.

Nawawi, H. 2001. Manajemen Sumber Daya Manusia. Yogyakarta: Gadjah Mada University Press.

Nengsy, H., Sari, R, N., \& Agusti, R. 2013. Pengaruh Partisipasi Penyusunan Anggaran terhadap Kinerja Manajerial dengan Job relevant information, Kepuasaan Kerja, dan
Motivasi sebagai Variabel Intervening. Jurnal Akuntansi 2 (1).

Pratiwi, Y, Sari. 2005. Pengaruh Partisipasi Anggaran, Job Relevant Information (JRI) dan Volatilitas Lingkungan terhadap Kinerja Manajerial. Skripsi. Universitas Katolik Soegijapranata Semarang. Dipublikasikan.

Putra, A. 2014. Pengaruh Partisipasi dalam Penyusunan Anggaran Terhadap Kinerja Manajerial pada SKPD Kabupaten Buleleng melalui Komitmen Organisasi, Kecukupan Anggaran, Komitmen Tujuan Anggaran dan Job relevant information sebagai Variabel Moderating. Skripsi. Universitas Pendidikan Ganesha. Singaraja

Santoso, S. 2004. Dinamika Kelompok. Jakarta: Bumi Aksara.

Sari, F. 2013. Pengaruh Kepemimpinan dan Motivasi Kerja Terhadap Kinerja Karyawan Galeri Ceumbuleuit Hotel dan Apartemen Bandung. Universitas Pasundan

Simamora, H. 2006. Manajemen Sumber Daya Manusia, edisi 2. Yogyakarta: STIE YKPN

Usman, Z. 2013. Pengaruh Sistem Pengendalian Intern Terhadap Kinerja Perusahaan Pada PT. MNC Sky Vision Cabang Gorontalo. Skripsi. Fakultas Ekonomi, Universitas Gorontalo.

Winadarta, N. 2003. Analisis Pengaruh Partisipasi Penyusunan Anggaran Terhadap Kinerja Manajerial Dengan Kultur Organisasi Dan Locus Of Control Sebagai Moderating. Tesis. Program Pasca Sarjana,Universitas Diponegoro. Semarang.

Windayani. 2013. Pengaruh Komunikasi dan Motivasi Terhadap Kinerja Karyawan pada Dinas Perhubungan Kabupaten Buleleng. Skripsi: Sekolah Tinggi Ilmu Ekonomi Singaraja.

Yunista, V. 2013. Kontribusi Kepemimpinan Dan Lingkungan Kerja Terhadap Kinerja Pegawai Bagian Keuangan Universitas Pendidikan Ganesha. Skripsi. Fakultas Ekonomi Dan Bisnis, Universitas Pendidikan Ganesha. Bali. 
Yusfaningrum, K. \& Ghozali, I. 2005.

Analisis Pengaruh Partisipasi

Anggaran Terhadap Kinerja

Manajerial Melalui Komitmen Tujuan

Anggaran dan Job relevant information (JRI) sebagai Variabel Intervening (Penelitian Terhadap Perusahaan Manufaktur Di Indonesia). Simposium Nasional Akuntansi VIII, Solo. 15 - 16 September .

2016. Metode Penilaian Kinerja. Universitas Narotama.

http://www.google.com 